\title{
Desempenho produtivo de ovelhas submetidas a acasalamentos no verão ou no outono no Norte do Paraná ${ }^{1}$
}

\section{Productive performance of ewes mated in summer or autumn in Northern Parana}

\author{
Edson Luis de Azambuja Ribeiro ${ }^{2 *}$; Ivone Yurika Mizubuti²; Leandro das Dores \\ Ferreira da Silva ${ }^{3}$; Marco Antonio da Rocha ${ }^{3}$; Rinaldo Masato Mori ${ }^{4}$
}

\section{Resumo}

\begin{abstract}
Este estudo teve por objetivo avaliar o desempenho produtivo de ovelhas acasaladas no verão ou no outono, durante quatro estações de acasalamento. Foram utilizadas 233 ovelhas, das raças Corriedale $(\mathrm{n}=55)$, Hampshire Down ( $\mathrm{n}=116)$, Ile de France $(\mathrm{n}=40)$ e Suffolk $(\mathrm{n}=22)$, com idades de 2 a 8 dentes. A parição foi maior $(\mathrm{P}<0,05)$ nas ovelhas acasaladas no outono $(89,1 \%)$ que no verão $(79,7 \%)$. Por outro lado, as taxas de desmame, de partos gemelares e de mortalidade dos cordeiros, e a produção de $\mathrm{kg}$ de cordeiros desmamados por kg de ovelha acasalada não diferiram $(\mathrm{P}>0,05)$ entre ovelhas acasaladas no verão e outono. Raça e idade da ovelha e ano de avaliação apresentaram influência $(\mathrm{P}<0,05)$ sobre os pesos e ganhos de peso das ovelhas e cordeiros, porém não afetaram $(\mathrm{P}>0,05)$ a produção de $\mathrm{kg}$ de cordeiros por kg de ovelha acasalada. Ovelhas, no norte do Paraná, podem ser acasaladas tanto no verão quanto no outono.
\end{abstract}

Palavras-chave: Fertilidade, monta, ovinos, parição, reprodução

\begin{abstract}
This study had the objective of evaluating the productive performance of ewes mated in summer or in autumn, during four breeding seasons. A total of 233 ewes, from the breeds Corriedale ( $\mathrm{n}=55)$, Hampshire Down ( $\mathrm{n}=116)$, Ile de France $(\mathrm{n}=40)$ and Suffolk ( $\mathrm{n}=22)$, with 2 to 8 teeth, were used. Lambing rate was greater $(\mathrm{P}<0.05)$ in ewes mated in autumn $(89.1 \%)$ than in summer $(79.7 \%)$. On the other hand, there were no differences $(\mathrm{P}>0.05)$ between ewes mated in autumn or summer for weaning, twin and lamb death rates, and for the production of $\mathrm{kg}$ of lambs per $\mathrm{kg}$ of mated ewe. Breed and age of ewe and year of evaluation influenced $(\mathrm{P}<0.05)$ the weights and weight gains of ewes and lambs, however, did not affect $(\mathrm{P}>0.05)$ the production of $\mathrm{kg}$ of lambs per $\mathrm{kg}$ of mated ewe. In the northern region of the Paraná state, ewes can be mated in summer or in autumn.
\end{abstract}

Key words: Breeding season, fertility, lambing, reproduction, sheep

Trabalho financiado pelo CNPq.

2 Professor do Depto. de Zootecnia, Bolsista CNPq. Universidade Estadual de Londrina, CCA, Depto. de Zootecnia. E-mail: elar@uel.br

3 Professor do Depto. de Zootecnia. UEL, CCA, Depto. de Zootecnia. Londrina, PR.

${ }^{4}$ Aluno de Pós-graduação em Ciência Animal. Depto. de Zootecnia - UEL. Londrina, PR.

* Autor para correspondência 


\section{Introdução}

A reprodução é considerada a maneira mais rápida e econômica para aumentar a produção ovina. Porém, para melhorar as diferentes características da reprodução devem-se utilizar, principalmente, práticas de manejo que visem melhorar os aspectos ambientais, pois as características reprodutivas possuem herdabilidades baixas, tendo pequenas respostas a seleção (ROSATI et al., 2002). Sendo a espécie ovina, de uma maneira geral, de poliestria estacional, um aspecto importante no manejo de um rebanho de cria é a época de acasalamento. O período reprodutivo difere segundo as raças e está relacionado com a latitude de origem (ROSA; BRYANT, 2003). O aparecimento de cios depende da luminosidade (relação luz/escuridão), que desencadeia os fenômenos hormonais que conduzem ao início da estação de reprodução. Outros fatores interagem com a luminosidade, podendo também afetar o aparecimento de cios, tais como: nutrição, temperatura, precipitação pluviométrica, peso vivo e condição corporal (MINOLA; GOYENECHEA, 1975; JAINUDEEN; HAFEZ, 1993; ROSA; BRYANT, 2003).

Vários experimentos conduzidos no Rio Grande do Sul com raças especializadas na produção de lã ou raças de duplo propósito, têm mostrado maiores desempenhos reprodutivos nos animais acasalados no outono. Durante o inverno e primavera há um marcado período de anestro (MIES FILHO; RAMOS, 1960; NUNES; FIGUEIRÓ, 1975; SILVA; FIGUEIRÓ, 1980; BASILE; MIES FILHO; SELAIVE-VILLARROEL, 1985). Além das maiores taxas de fertilidade e natalidade observadas em acasalamentos de outono, também tem sido observadas menores taxas de mortalidade de cordeiros e ovelhas acasaladas nesta época (SILVA; FIGUEIRÓ, 1980).

No estado de São Paulo, Prucolli e Baccari Júnior. (1967) observaram em ovelhas das raças Merino, Ideal e Corriedale, uma maior incidência de cios no final da primavera e início do verão. Por outro lado,
Sasa et al. (2001), no mesmo estado, observaram não haver sazonalidade reprodutiva em ovelhas da raça Santa Inês, mas em animais das raças Romney Marsh e Suffolk houve anestro fisiológico durante o período de julho a dezembro. No norte do Paraná, em um rebanho Hampshire Down, Ribeiro, Rocha e Silva (1996) e Ribeiro et al. (1999) observaram coberturas em todas as estações do ano, porém a maior atividade sexual foi observada nos meses de verão e outono.

Tendo em vista o exposto acima, este estudo teve por objetivo avaliar duas épocas de acasalamento, verão ou outono, sobre o desempenho reprodutivo das ovelhas, mortalidade dos cordeiros e produção de quilos de cordeiros ao desmame em um rebanho de ovelhas no norte do Paraná, além de avaliar os efeitos de grupamento genético e idade das ovelhas sobre estas características.

\section{Material e Métodos}

O estudo foi realizado no Setor de Ovinocultura da Fazenda Escola da Universidade Estadual de Londrina, Londrina, Paraná, durante quatro anos, iniciando em dezembro de 1999. A unidade experimental está localizada a $23^{\circ} 23^{\prime} \mathrm{S}$ de latitude e $51^{\circ} 11^{\prime} \mathrm{W}$ de longitude. Foi utilizado um total de 233 ovelhas das raças Corriedale $(\mathrm{n}=55)$, Hampshire Down ( $\mathrm{n}=116)$, Ile de France ( $\mathrm{n}=40)$ e Suffolk $(\mathrm{n}=22)$, com idades variando de 2 a 8 dentes. Do total de ovelhas, 50 foram utilizadas no primeiro ano, 50 no segundo, 77 no terceiro e 56 no quarto ano. As ovelhas foram distribuídas ao acaso, segundo o padrão racial e a idade, dentro de duas épocas de monta: T1 Acasalamento de verão ( 23 de dezembro a 05 de fevereiro; nascimentos em maio e julho) e T2 Acasalamento de outono (15 de março a 30 de abril; nascimentos em agosto e setembro).

Os animais foram mantidos em pastagem de grama Coastcross (Cynodon dactylon), tendo sal mineralizado a disposição em cochos apropriados. Os animais receberam suplementação no cocho com 
silagem de sorgo ou milho ( $\pm 2,0 \mathrm{~kg}$ por animal) de junho a setembro. O manejo sanitário foi o usual da propriedade, com controle da verminose feito conforme resultados de exames de fezes.

Anualmente foram utilizados dois carneiros Hampshire Down, dois Ile de France e dois Suffolk, sendo os mesmos colocados junto com as ovelhas das 18 às 8 horas diariamente. Os carneiros de cada raça foram colocados sobre ovelhas dos seus respectivos grupamentos genéticos, sendo que as ovelhas Corriedale foram distribuídas nos três grupos (Hampshire Down, Ile de France e Suffolk).

Foram medidos os pesos das ovelhas no início e final da época de acasalamento e ao parto, bem como os ganhos de peso durante o acasalamento e do final do acasalamento ao parto. Para avaliar o desempenho reprodutivo das ovelhas, foram medidas as taxas de parição ((ovelhas paridas/ovelhas acasaladas) x 100), de desmame ((ovelhas com cordeiros vivos ao desmame/ovelhas acasaladas) x 100), de partos gemelares ((partos gemelares/partos totais) x 100), além da prolificidade ao parto (cordeiros nascidos/ ovelhas paridas). Nos cordeiros avaliou-se além da mortalidade do nascimento ao desmame (70 dias de idade), os pesos ao nascimento e desmame e o ganho de peso médio diário. Visando avaliar a eficiência produtiva dos animais, mediu-se a produção de $\mathrm{kg}$ de cordeiros desmamados por $\mathrm{kg}$ de ovelhas paridas ou por $\mathrm{kg}$ de ovelha acasalada. Nos dois casos utilizou-se o peso das ovelhas no início do acasalamento.

Os dados foram submetidos a análise de variância e as características expressas em porcentagem foram comparadas pelo teste do qui-quadrado. $\mathrm{Na}$ análise de variância utilizou-se um modelo incluindo os efeitos de época de monta (verão e outono), raça da ovelha (Corriedale, Hampshire Down, Ile de France e Suffolk), idade da ovelha (2, 4, 6 e 8 dentes) e ano de avaliação (1, 2, 3 e 4). Para comparação entre médias utilizou-se o teste Tukey com significância de 5\% (SAS INSTITUTE, 1994).

\section{Resultados e Discussão}

Médias para os pesos e ganhos de peso das ovelhas são apresentadas na Tabela 1. Os pesos no início e final da monta, bem como o ganho de peso durante a monta, para as ovelhas acasaladas no verão ou no outono foram similares $(\mathrm{P}>0,05)$. Em ambas épocas observou-se que houve perda de peso das ovelhas do final da monta ao parto, algo esperado pois nos dois casos pelo menos parte da gestação ocorreu durante o inverno, onde a qualidade da pastagem não é boa, e a suplementação com silagem não foi suficiente para atender todas as exigências dos animais. As ovelhas acasaladas no verão perderam menos peso e conseqüentemente foram mais pesadas ao parto $(\mathrm{P}<0,05)$ que as acasaladas no outono, pois passaram um período menor da gestação no inverno quando comparadas com as acasaladas no outono. O ganho de peso ocorrido nas duas épocas de monta durante o acasalamento demonstra que a pastagem estava em melhores condições nestes períodos.

As ovelhas da raça Corriedale foram as mais leves $(\mathrm{P}<0,05)$ nas três pesagens, início e final do acasalamento e ao parto, sendo as mais pesadas as Suffolk, seguidas das Hampshire Down e depois pelas Ile de France. O maior peso das três raças de corte comparadas com a Corriedale era algo esperado, já que a raça Corriedale é de dupla aptidão (lã e carne). Em relação a perda de peso do final do acasalamento ao parto, a única diferença encontrada foi entre as ovelhas Ile de France e Hampshire Down, que apresentaram perdas de peso de 4,12 e 1,96 kg, respectivamente (Tabela 1 ).

A idade influenciou $(\mathrm{P}<0,05)$ o peso das ovelhas (Tabela 1). O peso aumentou em animais de dois aos oito dentes, onde animais mais jovens ( 2 dentes) foram sempre significativamente mais leves, não havendo diferença entre os pesos de animais de seis e oito dentes. As ovelhas de oito dentes foram as que menos ganharam peso durante o acasalamento e as de dois dentes foram as que menos perderam peso do final da monta ao parto. Em relação aos 
anos de avaliação, foi observada uma variação bastante grande para os pesos e ganhos de pesos entre os mesmos (Tabela 1). Demonstrando que os efeitos ambientais, principalmente em animais manejados a pasto, são importantes no seu desenvolvimento.

Tabela 1. Pesos (kg) e ganhos de pesos $(\mathrm{kg})$ das ovelhas.

\begin{tabular}{lccccc}
\hline Efeito & $\begin{array}{c}\text { Peso Início } \\
\text { Monta }\end{array}$ & $\begin{array}{c}\text { Peso Final } \\
\text { Monta (FM) }\end{array}$ & $\begin{array}{c}\text { Ganho Peso } \\
\text { Monta }\end{array}$ & Peso Parto & $\begin{array}{c}\text { Ganho } \\
\text { FM-Parto }\end{array}$ \\
\hline Época de monta & & & & & \\
$\quad$ Verão & 47,98 & 51,82 & 3,83 & $49,66 \mathrm{a}$ & $-2,09 \mathrm{a}$ \\
$\quad$ Outono & 46,78 & 51,04 & 4,28 & $47,11 \mathrm{~b}$ & $-3,97 \mathrm{~b}$ \\
Raça Ovelha & & & & & \\
$\quad$ Corriedale & $40,73 \mathrm{c}$ & $45,72 \mathrm{c}$ & 4,99 & $42,21 \mathrm{c}$ & $-3,42 \mathrm{ab}$ \\
$\quad$ Hampshire Down & $48,65, \mathrm{~b}$ & $52,06 \mathrm{~b}$ & 3,42 & $50,06 \mathrm{~b}$ & $-1,96 \mathrm{a}$ \\
$\quad$ Ile de France & $45,89 \mathrm{~b}$ & $49,21 \mathrm{bc}$ & 3,33 & $45,12 \mathrm{c}$ & $-4,12 \mathrm{~b}$ \\
$\quad$ Suffolk & $54,23 \mathrm{a}$ & $58,74 \mathrm{a}$ & 4,50 & $56,15 \mathrm{a}$ & $-2,60 \mathrm{ab}$ \\
Idade Ovelha (dentes) & & & & & \\
2 & $40,66 \mathrm{c}$ & $44,89 \mathrm{c}$ & $4,23 \mathrm{a}$ & $43,34 \mathrm{c}$ & $-1,41 \mathrm{a}$ \\
4 & $46,74 \mathrm{~b}$ & $51,55 \mathrm{~b}$ & $4,82 \mathrm{a}$ & $48,41 \mathrm{~b}$ & $-3,18 \mathrm{ab}$ \\
6 & $49,56 \mathrm{ab}$ & $53,77 \mathrm{ab}$ & $4,23 \mathrm{a}$ & $49,75 \mathrm{ab}$ & $-4,05 \mathrm{~b}$ \\
8 & $52,56 \mathrm{a}$ & $55,52 \mathrm{a}$ & $2,97 \mathrm{~b}$ & $52,04 \mathrm{a}$ & $-3,47 \mathrm{~b}$ \\
Ano & & & & & \\
1 & $49,92 \mathrm{a}$ & $49,57 \mathrm{~b}$ & $-0,36 \mathrm{c}$ & $46,78 \mathrm{bc}$ & $-2,85 \mathrm{ab}$ \\
2 & $43,64 \mathrm{~b}$ & $49,12 \mathrm{~b}$ & $5,49 \mathrm{ab}$ & $44,52 \mathrm{c}$ & $-4,65 \mathrm{~b}$ \\
3 & $46,11 \mathrm{~b}$ & $50,35 \mathrm{~b}$ & $4,23 \mathrm{~b}$ & $48,53 \mathrm{~b}$ & $-1,73 \mathrm{a}$ \\
4 & $49,84 \mathrm{a}$ & $56,69 \mathrm{a}$ & $6,84 \mathrm{a}$ & $53,73 \mathrm{a}$ & $-2,87 \mathrm{ab}$ \\
& & & & & $-3,03$ \\
\hline
\end{tabular}

a,b,c Médias na coluna, para o mesmo efeito, seguido por letras diferentes, diferem entre si $(\mathrm{P}<0,05)$.

As características reprodutivas são apresentadas na Tabela 2. As ovelhas acasaladas no outono apresentaram taxa de parição $9,5 \%$ maior $(\mathrm{P}<0,05)$ que as acasaladas no verão. Esse resultado foi semelhante ao de estudos anteriores (SILVA; FIGUEIRÓ, 1980; BASILE; MIES FILHO; SELAIVE-VILLARROEL, 1985). Como o ganho de peso durante o acasalamento foi similar $(\mathrm{P}>0,05)$ entre as épocas de monta, esta diferença pode ter ocorrido em função do fotoperíodo, ou seja, menor luminosidade no outono. Outros fatores não medidos podem, também, ter influenciado estes resultados, tais como temperatura ambiente, pluviosidade e qualidade das forragens, entre outros. Segundo Rosa e Bryant (2003) o fotoperíodo é o fator determinante na sazonalidade da atividade reprodutiva nos ovinos, afetando os mecanismos neuroendócrinos dos animais.

A prolificidade não diferiu $(\mathrm{P}>0,05)$ entre as épocas de monta. Minola e Goyenechea (1975) citaram que o ganho de peso durante a monta afeta a produção de gêmeos, mas provavelmente não tem efeito sobre a fertilidade, desde que as fêmeas estejam em boas condições corporais. Os autores ainda citam que ovelhas acasaladas no outono geralmente apresentam maior incidência de partos gemelares. Ribeiro et al. (1999), em condições semelhantes à do presente estudo, relataram incidência máxima de estros durante o outono, em 
um rebanho Hampshire Down. A taxa de mortalidade dos cordeiros também não diferiu $(\mathrm{P}>0,05)$ entre as épocas de monta, estando de acordo com os resultados encontrados por Roda et al. (1990a).

As taxas de parição e desmame e a prolificidade não diferiram $(\mathrm{P}>0,05)$ entre as raças, porém as ovelhas Hampshire Down apresentaram a menor taxa de partos gemelares $(\mathrm{P}<0,05)$. Cordeiros Hampshire Down apresentaram a menor taxa de mortalidade e os Suffolk a maior $(\mathrm{P}<0,05)$. Este fato está relacionado com a menor sobrevivência que é normalmente encontrada em cordeiros gêmeos. Isto pode facilmente ser visualizado na Tabela 2 , onde as percentagens de partos gemelares e de mortalidade dos cordeiros são bastante próximas. A exceção ocorreu com o grupamento Ile de France, onde a mortalidade dos cordeiros foi aproximadamente metade da taxa de partos gemelares, denotando uma melhor sobrevivência dos cordeiros gêmeos nesta raça. Roda et al. (1990b) observaram maior mortalidade em cordeiros gêmeos das raças Ideal e Corriedale que em cordeiros únicos. Roda, Santos e Cunha (1995) reportaram que cordeiros únicos que nasciam mais leves tendiam a ter uma maior taxa de mortalidade. No presente estudo os pesos dos cordeiros, quando gêmeos, foram apresentados somados, porém observou-se que os cordeiros gêmeos (individualmente) foram bem mais leves que os cordeiros únicos. A taxa de mortalidade média nas duas épocas de monta de $15,7 \%$ observada no presente trabalho é um pouco menor que as observadas (18\%) por Roda, Otto e Santos (1990a) em animais Ideal e Corriedale no estado de São Paulo, e por Ribeiro (1995) em cinco rebanhos no Rio Grande do Sul.

Tabela 2. Desempenho reprodutivo das ovelhas e mortalidade dos cordeiros.

\begin{tabular}{lccccc}
\hline Efeito & $\begin{array}{c}\text { Parição } \\
\mathbf{( \% )}\end{array}$ & $\begin{array}{c}\text { Partos } \\
\text { Gemelares } \\
\mathbf{( \% )}\end{array}$ & $\begin{array}{c}\text { Prolificidade } \\
\left(\mathbf{n}^{\mathbf{0}}\right)\end{array}$ & $\begin{array}{c}\text { Mortalidade } \\
\text { Cordeiros } \\
\mathbf{( \% )}\end{array}$ & $\begin{array}{c}\text { Desmame } \\
\mathbf{( \% )}\end{array}$ \\
\hline Época de monta & & & & & \\
$\quad$ Verão & $79,67 \mathrm{~b}$ & 15,31 & 1,09 & 14,41 & 69,11 \\
$\quad$ Outono & $89,09 \mathrm{a}$ & 20,41 & 1,13 & 16,95 & 79,09 \\
Raça Ovelha & & & & & \\
$\quad$ Corriedale & 83,64 & $21,74 \mathrm{a}$ & 1,11 & $19,64 \mathrm{ab}$ & 70,91 \\
Hampshire Down & 84,48 & $9,18 \mathrm{~b}$ & 1,05 & $8,41 \mathrm{c}$ & 78,45 \\
Ile de France & 82,50 & $27,27 \mathrm{a}$ & 1,17 & $15,00 \mathrm{bc}$ & 72,50 \\
Suffolk & 86,36 & $36,84 \mathrm{a}$ & 1,12 & $38,46 \mathrm{a}$ & 59,09 \\
Idade Ovelha (dentes) & & & & & \\
2 & 78,79 & $1,92 \mathrm{~b}$ & $1,02 \mathrm{~b}$ & 13,21 & 69,70 \\
4 & 91,89 & $11,76 \mathrm{ab}$ & $1,04 \mathrm{~b}$ & 10,53 & 86,49 \\
6 & 88,57 & $29,03 \mathrm{a}$ & $1,20 \mathrm{a}$ & 15,00 & 80,00 \\
8 & 83,16 & $26,58 \mathrm{a}$ & $1,18 \mathrm{a}$ & 19,39 & 69,47 \\
Ano & & & & \\
1 & $86,00 \mathrm{a}$ & 16,28 & 1,12 & 20,00 & 70,00 \\
2 & $72,00 \mathrm{~b}$ & 8,33 & 1,07 & 12,82 & 64,00 \\
3 & $85,71 \mathrm{a}$ & 15,15 & 1,10 & 11,84 & 81,82 \\
4 & $91,07 \mathrm{a}$ & 29,41 & 1,15 & 18,75 & 75,00 \\
Média geral & & & & & 74,10 \\
\hline
\end{tabular}

a,b,c Médias na coluna, para o mesmo efeito, seguido por letras diferentes, diferem entre si $(\mathrm{P}<0,05)$. 
Em relação a idade das ovelhas foi observada diferença $(\mathrm{P}<0,05)$ na percentagem de partos gemelares, que foi significativamente menor nas ovelhas de dois dentes, e na prolificidade ao parto, onde ovelhas de dois e quatro dentes apresentaram menor desempenho (Tabela 2). Estes resultados estão de acordo com Minola e Goyenechea (1975) que citaram que borregas de dois dentes apresentaram menor taxa ovulatória e menor percentagem de partos gemelares. Houve influência do ano de avaliação sobre as percentagens de parição $(\mathrm{P}<0,05)$, porém, as percentagens de desmame, partos gemelares e a mortalidade dos cordeiros, não foram afetadas $(\mathrm{P}>0,05)$. Em ambientes onde o inverno é mais rigoroso, com temperaturas mais baixas e elevada precipitação pluviométrica, cordeiros nascidos nesta estação, tendem a ter uma mortalidade mais elevada (SILVA; FIGUEIRÓ, 1980; RIBEIRO, 1995).

Médias para os pesos ao nascimento e desmame (70 dias) e para o ganho médio diário até o desmame são apresentadas na Tabela 3. Cordeiros resultantes dos acasalamentos de verão ou outono apresentaram pesos e ganhos de pesos similares $(\mathrm{P}>0,05)$, porém os outros efeitos testados afetaram $(\mathrm{P}<0,05)$ estas variáveis, com exceção do peso ao nascimento entre os grupamentos genéticos, que foram muito próximos, com média geral de 3,79 kg. Roda et al. (1990a) também não observaram, na raça Corriedale, diferenças nos pesos e ganhos de peso de cordeiros nascidos no inverno ou primavera.

Os cordeiros Suffolk foram os que mais ganharam peso do nascimento ao desmame e os mais pesados ao desmame $(\mathrm{P}>0,05)$, porém, não diferiram significativamente dos cordeiros Hampshire Down. Os cordeiros Ile de France apresentaram pesos e ganhos de pesos intermediários, e os cordeiros filhos de ovelhas Corriedale apresentaram o menor ganho de peso e foram os mais leves ao desmame. Cabendo salientar que os cordeiros das ovelhas Corriedale eram filhos de carneiros das três raças de corte citadas.

Tabela 3. Pesos (kg) e ganhos médios diários de peso (GMD, kg) do nascimento ao desmame dos cordeiros.

\begin{tabular}{lccc}
\hline Efeito & Peso Nascimento & Peso Desmame & GMD \\
\hline Época de monta & 3,74 & 15,18 & 0,163 \\
$\quad$ Verão & 3,84 & 15,49 & 0,166 \\
$\quad$ Outono & 3,78 & $13,73 \mathrm{c}$ & $0,140 \mathrm{c}$ \\
Raça Ovelha & 3,88 & $15,90 \mathrm{ab}$ & $0,171 \mathrm{ab}$ \\
$\quad$ Corriedale & 3,78 & $14,49 \mathrm{bc}$ & $0,154 \mathrm{bc}$ \\
$\quad$ Hampshire Down & 3,72 & $17,21 \mathrm{a}$ & $0,193 \mathrm{a}$ \\
Ile de France & & & \\
Suffolk & $3,31 \mathrm{~b}$ & $13,60 \mathrm{c}$ & $0,150 \mathrm{~b}$ \\
Idade Ovelha (dentes) & $3,45 \mathrm{~b}$ & $14,76 \mathrm{bc}$ & $0,160 \mathrm{ab}$ \\
2 & $4,41 \mathrm{a}$ & $16,89 \mathrm{a}$ & $0,177 \mathrm{a}$ \\
4 & $3,99 \mathrm{a}$ & $16,07 \mathrm{ab}$ & $0,174 \mathrm{a}$ \\
6 & & & \\
8 & $3,50 \mathrm{~b}$ & $14,42 \mathrm{~b}$ & $0,155 \mathrm{~b}$ \\
Ano & $3,54 \mathrm{~b}$ & $14,67 \mathrm{~b}$ & $0,159 \mathrm{~b}$ \\
1 & $3,88 \mathrm{ab}$ & $13,78 \mathrm{~b}$ & $0,141 \mathrm{~b}$ \\
2 & $4,24 \mathrm{a}$ & $18,46 \mathrm{a}$ & $0,203 \mathrm{a}$ \\
3 & & & \\
4 & 3,79 & 15,34 & 0,165 \\
\hline
\end{tabular}

a,b,c Médias na coluna, para o mesmo efeito, seguido por letras diferentes, diferem entre si $(\mathrm{P}<0,05)$. 
Ovelhas mais jovens ( 2 e 4 dentes) apresentaram cordeiros mais leves ao nascimento e com menor ganho de peso até o desmame, e conseqüentemente apresentaram cordeiros mais leves ao desmame que ovelhas e seis e oito dentes (Tabela 3). Este resultado era esperado, pois animais nestas idades ainda encontram-se em crescimento, e normalmente produzem menos leite para os cordeiros (MINOLA; GOYENECHEA, 1975). Com relação ao ano de avaliação, os maiores pesos e ganhos de peso foram observados no último ano, não havendo diferenças entre os outros anos (Tabela 3).
Médias para as medidas de produtividade, $\mathrm{kg}$ de cordeiro desmamado por kg de ovelha parida ou por $\mathrm{kg}$ de ovelha acasalada, são apresentadas na Tabela 4. A única diferença observada foi para o efeito de ano sobre a produção de $\mathrm{kg}$ de cordeiro por $\mathrm{kg}$ de ovelha parida. Por ter havido uma maior taxa de parição e não ter tido diferenças na taxa de mortalidade e no peso dos cordeiros ao desmame, esperava-se uma maior produtividade nas ovelhas acasaladas no outono. O que deve ter influenciado este resultado foi a taxa de mortalidade dos cordeiros, que apesar de não significativa teve um efeito importante, diminuindo a produtividade total.

Tabela 4. Medidas de produtividade das ovelhas.

\begin{tabular}{lcc}
\hline Efeito & $\begin{array}{c}\text { kg de cordeiro desmamado / kg de } \\
\text { ovelha parida }\end{array}$ & $\begin{array}{c}\text { kg de cordeiro desmamado / } \\
\text { kg de ovelha acasalada }\end{array}$ \\
\hline Época de monta & 0,32 & 0,28 \\
$\quad$ Verão & 0,34 & 0,29 \\
$\quad$ Outono & 0,32 & \\
Raça Ovelha & 0,33 & 0,31 \\
Corriedale & 0,33 & 0,30 \\
Hampshire Down & 0,33 & 0,29 \\
Ile de France & & 0,24 \\
Suffolk & 0,34 & \\
Idade Ovelha (dentes) & 0,31 & 0,28 \\
2 & 0,34 & 0,30 \\
4 & 0,32 & 0,31 \\
6 & & 0,26 \\
8 & $0,30 \mathrm{c}$ & 0,25 \\
Ano & $0,34 \mathrm{~b}$ & 0,29 \\
1 & $0,30 \mathrm{c}$ & 0,28 \\
2 & $0,38 \mathrm{a}$ & 0,31 \\
3 & & 0,29 \\
4 & 0,33 & \\
\hline
\end{tabular}

${ }_{\text {a,b,c }}$ Médias na coluna, para o mesmo efeito, seguido por letras diferentes, diferem entre si $(\mathrm{P}<0,05)$. 


\section{Conclusões}

O acasalamento de ovelhas no norte do Paraná pode ser realizado tanto no verão como no outono.

Ovelhas de raças de corte, ou de duplo propósito acasaladas com reprodutores de corte, apresentam produtividade similar, porém, cordeiros de raças de corte, definidos, são mais pesados ao desmame.

Borregas apresentam desempenho reprodutivo menor e cordeiros mais leves ao desmame que ovelhas com mais idade.

\section{Referências}

BASILE, B. H.; MIES FILHO, A.; SELAIVE-VILLARROEL, A. B. Indução da atividade sexual em ovelhas Corriedale mediante controle da luminosidade. Semina, Londrina, v.6, n.3, p.125-132, 1985.

JAINUDEEN, M. R.; HAFEZ, E. S. E. Reproductive cycles: sheep and goats. In: HAFEZ, E. S. E. (Ed.) Reproduction in farm animals. 6.ed. Philadelphia: Lea \& Febiger, 1993. p.330-342.

MIES FILHO, A.; RAMOS, A. A. Ciclo estral de ovelhas no Brasil. Revista da Escola de Agronomia e Veterinária da UFRGS, Santa Maria, v.3, p.57-63, 1960.

MINOLA, J.; GOYENECHEA, J. Praderas \& lanares: producción ovina en alto nivel. Montevideo: Hemisferio Sur, 1975.

NUNES, J. F.; FIGUEIRÓ, P. R. P. Fatores que afetam o comportamento reprodutivo em ovelhas Corriedale e Polwarth. Revista do Centro de Ciências Rurais, Santa Maria, v.5, n.4, p.301-307, 1975.

PRUCOLLI, J. O.; BACCARI JÚNIOR, F. L. Estudos sobre a estação de monta em ovinos no estado de São Paulo. Boletim de Indústria Animal, Nova Odessa, v.124, p.7580, 1967.

RIBEIRO, L. A. O. Perdas reprodutivas em ovinos no Rio Grande do Sul: causas e soluções. In: SIMPÓSIO PAULISTA DE OVINOCULTURA, 4., 1995, Campinas. Anais... Campinas: CATI, 1995. p.113-124.

RIBEIRO, E. L. A.; ROCHA, M. A.; SILVA, L. D. F. Aspectos reprodutivos em ovelhas Hampshire Down submetidas a monta contínua na região norte do Paraná. Revista da Sociedade Brasileira Zootecnia, Viçosa, v.25, n.4, p.637646, 1996.
RIBEIRO, E. L. A.; SILVA, L. D. F.; ROCHA, M. A.; MIZUBUTI, I. Y. Efeito de coberturas iniciadas na primavera ou no verão sobre o desempenho reprodutivo de ovelhas Hampshire Down. Semina: Ciências Agrárias, Londrina, v.20, n.1, p.39-43, 1999.

RODA, D. S.; OTTO, P. A.; SANTOS, L. E.; DUPAS, W. Efeito da época do nascimento na sobrevivência e desenvolvimento de cordeiros das raças Ideal e Corriedale. Boletim de Indústria Animal, Nova Odessa, v.47, n.1, p.8187,1990 a.

RODA, D. S.; OTTO, P. A.; SANTOS, L. E.; DUPAS, W.; FEITOZA, A. S. L.; BIANCHINI, D. Efeito do tipo de gestação (simples ou gemelar) na sobrevivência e desenvolvimento de cordeiros das raças Ideal e Corriedale. Boletim de Indústria Animal, Nova Odessa, v.47, n.2, p.115-119, 1990b.

RODA, D. S.; SANTOS, L. E.; CUNHA, E. A. Peso ao nascer e mortalidade pré-desmame em cordeiros das raças Ideal e Corriedale. Boletim de Indústria Animal, Nova Odessa, v.52, n.1, p.67-70, 1995.

ROSA, H. J. D.; BRYANT, M. J. Seasonality of reproduction in sheep. Small Ruminant Research, Amsterdam, v.48, p.155-171, 2003.

ROSATI, A.; MOUSA, E.; VAN VLECK, L. D.; YOUNG, L. D. Genetic parameters of reproductive traits in sheep. Small Ruminant Research, Amsterdam, v.43, p.65-74, 2002.

SAS INSTITUTE. SAS/STAT User's Guide. Cary: SAS Institute Inc., 1994. v.2.

SASA, A.; TESTON, D. C.; SILVA, E. C. F.; CRIVELLENTI, T. L.; PORTO, M. S. C. S.; RODRIGUES, P. A.; COELHO, L. A. Perfil plasmático de progesterona e incidência mensal de ovulações silenciosas em borregas lanadas e deslanadas criadas no estado de São Paulo. In: CONGRESSO BRASILEIRO DE ZOOTECNIA, 21., 2001, Goiânia. Anais... Goiânia: Associação Brasileira de Zootecnia, 2001.p.16.

SILVA, O. L.; FIGUEIRÓ, P. R. P. Efeito da época de cobertura sobre a fertilidade de ovelhas e mortalidade de cordeiros na raça Corriedale. In: REUNIÃO ANUAL DA SOCIEDADE BRASILEIRA DE ZOOTECNIA, 27., 1980, Fortaleza. Anais... Fortaleza: Sociedade Brasileira de Zootecnia, 1980. p.127. 